University of Nebraska - Lincoln

DigitalCommons@University of Nebraska - Lincoln

Public Health Resources

Public Health Resources

2001

\title{
Helmet Laws and Motorcycle Rider Death Rates
}

Charles C. Branas

University of Pennsylvania School of Medicine and Philadelphia Veterans Affairs Medical Center, 807

Blockley Hall, 423 Guardian Drive, Philadelphia, PA

M. Margaret Knudson

University of California, San Francisco

Follow this and additional works at: https://digitalcommons.unl.edu/publichealthresources

Part of the Public Health Commons

Branas, Charles C. and Knudson, M. Margaret, "Helmet Laws and Motorcycle Rider Death Rates" (2001). Public Health Resources. 12.

https://digitalcommons.unl.edu/publichealthresources/12

This Article is brought to you for free and open access by the Public Health Resources at DigitalCommons@University of Nebraska - Lincoln. It has been accepted for inclusion in Public Health Resources by an authorized administrator of DigitalCommons@University of Nebraska - Lincoln. 


\title{
Helmet laws and motorcycle rider death rates
}

\author{
Charles C. Branas ${ }^{\mathrm{a}, *}$, M. Margaret Knudson ${ }^{\mathrm{b}}$ \\ a Department of Biostatistics and Epidemiology, \\ University of Pennsylvania School of Medicine and Philadelphia Veterans Affairs Medical Center, 807 Blockley Hall, 423 Guardian Drive, \\ Philadelphia, PA 19104-6021, USA \\ b Department of Surgery, San Francisco General Hospital, University of California, San Francisco, 1001 Potrero Avenue, Ward 3A-Box 0807, \\ San Francisco, CA 94110, USA
}

Received 28 September 1999; received in revised form 28 July 2000; accepted 11 August 2000

\begin{abstract}
We investigated motorcycle rider death rates between states with full motorcycle helmet laws and those without. This was done using both unadjusted bivariate analyses and multivariate random-effects generalized least squares regression models of rider death rates. Multivariate models were adjusted for the competing influences of several explanatory variables, including the existence of a motorcycle helmet law. From 1994 to 1996, states with helmet laws experienced a median death rate of 6.20 riders per 10000 registered motorcycles and states without helmet laws experienced a median death rate of 5.07 riders per 10000 registered motorcycles $(P=0.008)$. After controlling for other factors that affect motorcycle rider fatalities (most notably population density and temperature), death rates in states with full helmet laws were shown to be lower on average than deaths rates in states without full helmet laws $(P=0.740)$. Our study weakens the claim that rider death rates are significantly lower in states without full motorcycle helmet laws.
\end{abstract}

Keywords: Injury; Motor vehicles; Motorcycle helmets; Health policy

\section{Background}

Studies analyzing motorcycle rider fatalities in the medical literature have uniformly recommended helmet laws as a means to prevent deaths among motorcyclists in the US (Sosin et al., 1990; Fleming and Becker, 1992; Muelleman et al., 1992; Kraus et al., 1994; Sarkar et al., 1995; Mock et al., 1995; Rowland et al., 1996). The nonmedical literature has made similar recommendations, although less uniformly. Nonmedical reports outlining the paradoxical effects of motorcycle helmet laws have offered useful contradictory evidence for consideration by lawmakers (Goldstein, 1986; Graham and Lee, 1986). Most recently, a report from the US Department of Transportation's National Highway Traffic Safety Administration (NHTSA) has brought to light the finding that motorcycle fatality rates are lower in states

\footnotetext{
* Corresponding author. Tel.: + 1-215-5735381; fax: + 1-2155735315.

E-mail address: cbranas@cceb.med.upenn.edu (C.C. Branas).
}

without helmet laws (National Highway Traffic Safety Administration, 2000).

Although these studies describe the relationship between the existence of helmet laws and motorcycle rider death rates, they do not simultaneously account for the intervening effects of other variables such as population density, weather, alcohol consumption, and urban versus rural roads. Our study seeks to build on previous work, in both the medical and nonmedical literature, by better investigating the finding that motorcycle rider death rates are significantly lower in states without helmet laws.

\section{Methods}

\subsection{Statistical modeling}

The goal of our study was to complete a national, State-based analysis of motorcycle rider death rates in the US. Counts of motorcycle rider deaths for all the 50 states and the District of Columbia were obtained from NHTSA's Fatality Analysis Reporting System (FARS) 
for the years 1994, 1995, and $1996^{1}$. These 3 years were selected as a recent period of time over which no changes to State motorcycle helmet laws had occurred and in which the breakdown of states with full motorcycle helmet laws and those without was nearly even. The FARS contains data on a census of fatal traffic crashes within the 50 states and the District of Columbia. To be included in the FARS database, a crash must involve a motor vehicle traveling on a public roadway and result in the death of a person (driver, passenger, or non-occupant) within 30 days of the crash. To complement our count of motorcycle rider deaths, the total number of private, commercial, and publicly owned motorcycles that were registered per State was also obtained for the same 3 years from the US Department of Transportation, Federal Highway Administration's Annual Highway Statistics Series (Federal Highway Administration, 2000). These two variables were used to create the dependent variable, deaths per 10000 registered motorcycles per State. Our final database consisted of 153 records over a 3-year study period, 51 records per year.

The status of motorcycle helmet use requirements was separately determined for all the 50 states and the District of Columbia for the years, 1994, 1995, and 1996. This became our policy variable of interest. No states or the District of Columbia changed their motorcycle helmet use policies over the 3-year study period (National Highway Traffic Safety Administration, 1996). Three states did successfully debate changing their helmet use requirements during the study period, although in each - Texas ${ }^{2}$, Arkansas ${ }^{3}$ and Kentucky ${ }^{4}$ - the new policies were not legally implemented until 1-2 years after the study period (National Highway Traffic Safety Administration, 1999) (Insurance Institute for Highway Safety, 1997).

Across all the 50 states and the District of Columbia there were three types of motorcycle helmet use regulations full laws, no laws, and partial laws. Over the study period, 25 states and the District of Columbia had full motorcycle helmet laws. Full laws are requirements that all motorcycle riders wear helmets. Only three states Colorado, Illinois, and Iowa - had no laws requiring helmet use over the study period. The remaining 22 states had partial laws indicating that only persons under a specific age were required to wear motorcycle helmets. In 19 of these partial law states the age threshold was 18 years old, in one (Maine) it was 15 years old, in one (Delaware) it was 19 years old, and in one (Rhode Island) it was 21 years old.

\footnotetext{
${ }^{1}$ This information was downloaded via file-transfer-protocol at: http://www-fars.nhtsa.dot.gov/.

${ }^{2}$ Changes to Texas Transportation Code $\$ 3.661 .003(\mathrm{c})$ went into effect in September, 1997.

${ }^{3}$ Changes to Arkansas Code No.453 §1.27-20-104(b) went into effect in July, 1997.

${ }^{4}$ Changes to Kentucky Revised Statute Chap.21 §1.189.285.3(a) went into effect in July, 1998
}

Since underage motorcycle crash deaths in partial law states would have to be independently treated as if they had occurred in full law states and because these deaths were in such small numbers (based on the FARS data, the median percentage of underage decedents in each partial law State was $2.0 \%$ in $1994,0.5 \%$ in 1995 , and $2.1 \%$ in 1996), we excluded underage deaths in partial law states. Our decision to exclude these few deaths was further supported by the fact that helmet use rates in states with no laws and in states with partial laws have been very similar in the past (National Highway Traffic Safety Administration, 1996).

Of the 22 partial law states, 14 had underage deaths (typically 1-2 deaths per year) that were excluded. In these 14 states, the total number of registered motorcycles was also changed using state data multipliers from the US Census Bureau to reflect the age-based exclusion. This decreased the number of registered motorcycles variable for all the states by $0.93 \%$, a minor margin that did not remarkably affect any of our conclusions. After the exclusion of and adjustment for these relatively few underage deaths, states with partial helmet laws were treated as if they had no motorcycle helmet use requirements. In our final analysis then, a total of 25 states and the District of Columbia were marked as having helmet use laws and the remaining 25 states were marked as having no helmet use laws.

All the statistical analyses were done using Intercooled STATA version 6.0 (Stata Corporation, College Station, TX, USA). Bivariate analyses were conducted to compare states with helmet laws and those without helmet laws. Since it was determined that the dependent variable, deaths per 10000 registered motorcycles, was markedly non-normal (with a skewness coefficient = 3.46), nonparametric Wilcoxon's rank-sum tests were used to initially compare states with helmet laws and those without helmet laws. Other bivariate analyses were completed using Student's $t$-tests.

Multivariate regression models were adjusted for characteristics of risk related to the decedents themselves (i.e. a variable such as the average engine size of motorcycles ridden by decedents in each State) and for characteristics of population-wide risk (i.e. a variable such as the per capita alcohol consumption in each State). All the multivariate regressions were specified as random-effects models using a generalized least squares estimator. This produced a matrix-weighted average of the estimates resulting from both between-State and within-State estimators.

Random effects estimators respond to the problem that variables may intrinsically vary between states and within states over time. Our random effects models assumed that repeated observations per State per year were independent, but that correlation among repeated observations arose because we could not observe underlying, year-to-year changes in each State (Diggle et al., 
1995). We chose regression models with random effects estimators because our variable measurements were imperfect within each State due to a serially correlated omitted variable bias. Therefore, the random effects models we used were able to evaluate the impact of motorcycle helmet laws by comparing a State's motorcycle crash experience against itself (National Highway Traffic Safety Administration, 1999) and other states.

All multivariate models were tested for nonconstant variance using Spearman rank-order correlations and Glejser regressions (Glejser, 1969). After the natural-log transformation of the dependent variable, deaths per 10000 registered motorcycles, no significant heteroscedasticity was noted in our final multivariate model. Individual coefficients were assessed using $z$ statistics and $90 \%$ confidence intervals, and overall model fit was assessed using $R^{2}$ statistics. Hausman specification tests were also conducted to check the appropriateness of the random-effects estimator. Our final multivariate model was correctly specified with a random-effects estimator by Hausman's specification test $\left(\chi^{2}=4.66\right)$. Post hoc power calculations were also completed to assess the accuracy of negative results (Diggle et al., 1995). $P$-values less than 0.10 were considered statistically significant throughout all analyses.

\subsection{Independent variable selection}

Collinear independent variables were identified using Spearman's correlation coefficients, tolerance statistics, and condition indices. Severe multicollinearity prompted the elimination of one or more collinear covariates. Only sufficiently noncollinear covariates were used in our final model. This prompted us to rule out variables such as motorcycle helmet usage in each State and years since the establishment of each State's helmet law because these two variables were highly collinear with the existence of a motorcycle helmet law. Moreover, we did not include the variable hospitals per square mile (as a measure of access to medical care) in our final model because it was highly collinear with population density.

We also chose not to include a measure of vehicle miles traveled per State for motorcycles. This decision was chiefly motivated by the fact that vehicle miles traveled are not uniformly collected on all roadways for specific vehicle types including motorcycles. Thus, the vehicle miles traveled variable calculated by the Federal Highway Administration can provide generalized travel distributions by vehicle type although it is not appropriate for State-by-State estimations of vehicle miles traveled by vehicle type (Federal Highway Administration, 2000).

After ruling out inappropriate predictors, we analyzed the competing influences of the following vari- ables on the death rates of motorcyclists (1) population density; (2) weather; (3) alcohol consumption; (4) maximum speed limit; (5) urban versus rural roads; (6) motorcycle engine size; and (7) age. We justified the inclusion of these variables based on their previously hypothesized effects on motorcycle fatalities in particular and/or highway fatalities in general.

We calculated population density as the number of State residents per 10 square miles. Both the number of residents as well as the square mile land area of each State and the District of Columbia were obtained for the years 1994-1996 from the Census Bureau (Yax, 2000). Population density has been hypothesized to specifically affect motorcycle rider death rates (National Highway Traffic Safety Administration, 2000) as well as highway fatality rates in general. Higher population densities imply driving environments with more frequent stops as opposed to lower densities which are associated with more uninterrupted driving environments (Keeler, 1994). In this way, higher population density should decrease the likelihood of motorcycle rider fatalities.

Two variables were used to represent the weather conditions in each State and the District of Columbia: average temperature (measured in Fahrenheit degrees) and average precipitation (measured in inches per month). Both variables were obtained for the years 1994-1996 from the National Oceanic and Atmospheric Administration (Lott, 2000). These variables are reported as averages because they are calculated from data collected at multiple climatological stations in each State. Weather, in general, has been hypothesized to affect motorcycle rider death rates (National Highway Traffic Safety Administration, 2000). More specifically, temperature and precipitation are likely to affect motorcycle fatality rates because they each change the length of the riding season in each state. States with high temperatures and low precipitation (such as in the southwestern US) will presumably have longer riding seasons and therefore greater opportunity for motorcycle fatalities to occur. Alternatively, states with low temperatures and high precipitation (such as in the northeastern US) will have shorter riding seasons and fewer motorcycle fatalities.

The influence of alcohol on motorcycle death rates was represented in our models by the per capita alcohol consumption in each State and the District of Columbia. Per capita alcohol consumption data were obtained from the US Department of Health and Human Services National Institute of Alcohol Abuse and Alcoholism for the years 1994-1996. These data were calculated for populations aged 14 and older and were measured in gallons of ethanol (beer, wine, and spirits) (National Institute on Alcohol Abuse and Alcoholism, 2000). A per capita alcohol consumption variable has been previously applied to the study of highway fatality 
rates across all vehicle types (Keeler, 1994). This variable's use for the specific study of motorcycle fatality rates seems all the more appropriate when considering that motorcycle drivers have the highest frequency of alcohol use among all drivers and that around one-half of all motorcycle drivers who crash test positive for alcohol (Peek-Asa and Kraus, 1996; Bolhofner et al., 1994; Soderstrom et al., 1993). Therefore, because alcohol consumption is an important factor in motorcycle crashes we would expect that higher rates of alcohol consumption will correspond with higher motorcycle rider fatality rates.

The influence of speed on motorcycle rider fatalities was modeled using the maximum speed limit in each State and the District of Columbia. Maximum State speed limits (measured in miles-per-hour) in each State were obtained for 1994-1996 from the NHTSA and the Insurance Institute for Highway Safety (National Highway Traffic Safety Administration, 1998; Insurance Institute for Highway Safety, 1999, 2000). Unlike observed vehicle speeds, publicly imposed speed limits were determined outside of the current regression model in the same way as temperature and rainfall (Gujarati, 1988). From the viewpoint of public policy then, the maximum speed limit in each State is exogenous (Keeler, 1994) and we have included it in our model of motorcycle rider fatality rates. Moreover, because in most states this limit applies mainly to interstate-quality divided highways, the population density variable has been included to control for situations in which more urbanized areas have little occasion to use the maximum speed limit (Keeler, 1994). Thus, we anticipate that motorcycle rider death rates should increase as riders are legally permitted to drive faster, on average, in states with higher maximum speed limits.

Since states differ extensively in terms of urban versus rural roads, we included a percentage of urban roads per State variable in our modeling of motorcycle rider deaths. The percentage of urban roads in each State and the District of Columbia was obtained from the Federal Highway Administration (Federal Highway Administration, 2000) for the years 1994-1996 and was calculated as: urban mileage/(rural mileage + urban mileage). By using the percentage of urban roads, as opposed to total urban road miles, we were better able to measure urban roads in relation to rural roads. The urban traffic environment has been hypothesized to differentially affect State motorcycle rider death rates compared with nonurban environments (National Highway Traffic Safety Administration, 2000; Lund et al., 1991). We, therefore, expect that due to lower average travel speeds and more frequent stops, states with higher percentages of urban roads will have fewer motorcycle rider deaths per registered motorcycle.

We also incorporated engine displacement into our model of motorcycle rider death rates. To create this variable, the motorcycle engine displacement (in cubic centimeters) of motorcycle riders who died in each year of the study period was queried from the FARS for each State and the District of Columbia. This variable described the variations in risk that deceased riders had experienced prior to their death and was used a surrogate for the potential differences in population-wide risk experienced by states with different sizes of motorcycles in circulation. Based on previous work investigating motorcycle engine displacement (Kraus et al., 1988), this variable will likely have an inverse relationship with rider death rates.

Two variables were used to quantify age in each State and the District of Columbia: median age per State and the average age of motorcycle rider decedents. Estimates of median age were obtained for the years 1994-1996 from the US Census Bureau (Yax, 2000). The average age of motorcycle riders who died in each year of the study period was queried from the FARS. These two variables were not collinear and offered distinct information to our final regression model. Based on previous studies, we speculate that states with lower median ages and younger motorcycle rider decedents will have higher fatality rates (Sosin et al., 1990; Baker et al., 1992).

\section{Findings}

Although the number of deaths and the number of motorcycle registrations had large standard deviations, deaths per 10000 registered motorcycles demonstrated relatively little variation. Based on our bivariate analyses, states with helmet laws had significantly higher average temperatures over the 3-year study period compared to states without full helmet laws $(P<0.05)$. States with helmet laws also had significantly lower average engine displacement compared to states without full helmet laws $(P<0.05)$. (Table 1)

Our bivariate analyses also demonstrated that states with motorcycle helmet laws had significantly higher death rates per 10000 registered motorcycles compared to states without helmet laws $(P<0.01)$. This difference became less striking when our entire state cohort was disaggregated by year and the $P$-values increased, although the difference between states with helmet laws and those without remained strong, particularly for 1994-1995 $(P<0.10)$. No remarkable trend in motorcycle rider death rates was noted across years. (Table 2)

After simultaneously adjusting for other factors using multivariate regression models, death rates in states with full motorcycle helmet laws were shown to be lower on average than death rates in states without helmet laws, although not significantly so. In support of this negative finding, a statistical power of $74.4 \%$ was demonstrated for three repeated measurements in 50 
states and the District of Columbia upon assuming a $10 \%$ type-I error rate and a $30 \%$ smallest meaningful difference in standard deviation (S.D.) units. Thus, in contrast to the previous bivariate analysis, simultaneously accounting for other factors (in addition to the existence of a motorcycle helmet law) reversed the average impact of State helmet laws on motorcycle rider deaths. (Table 3)

Other explanatory variables produced statistically significant regression coefficients. Increasing the population density of a State by one resident per 10 squaremiles corresponded with a $0.16 \%$ increase in the motorcycle rider death rate $(P<0.05)$. Even more significantly, a one degree increase in the average State temperature corresponded with a $3.84 \%$ increase in motorcycle rider death rates $(P<0.05)$. (Table 3$)$

\section{Discussion}

Motorcycle rider deaths comprised $9.3 \%$ of all the traffic deaths between 1994 and 1996 (Insurance Institute for Highway Safety, 1999). Head injury was a leading cause of death in these motorcycle crashes. Being unhelmeted, as a motorcyclist in a crash, substantially increases the risk of a fatal head injury. Therefore, because they primarily protect a rider's head, NHTSA estimates that motorcycle helmets reduce the likelihood of dying in a crash by as much as $29 \%$, saving hundreds of lives each year in the US (National Highway Traffic Safety Administration, 1999).
State laws requiring motorcycle riders to wear helmets are easily enforced due to the conspicuous nature of being unhelmeted. States with motorcycle helmet laws that require use among all riders, regardless of age, reportedly have had nearly complete compliance with the law. On the other hand, states with no helmet laws, or with laws that require usage only among minors, have helmet usage rates that are about one-half to two-thirds lower than their full law counterparts (National Highway Traffic Safety Administration, 1999).

Based on the posited mortality reducing effects of helmet usage, NHTSA has categorically recommended the implementation of motorcycle helmet laws for states that do not currently have them in place. This recommendation has had widespread support in the medical literature. Sosin et al. (1990) found that motorcycle rider death rates were higher in states with no helmet laws and partial helmet laws compared to states with full helmet laws. Although this study failed to control for cross-State differences such as speed and alcohol consumption, it did provide a reasonable comparative analysis at the national level. Other studies have assessed the effects of motorcycle helmet laws for individual states. Muelleman et al. (1992) documented a sharp decline in death rates after the reenactment of a comprehensive motorcycle helmet use law in Nebraska. Fleming and Becker (1992) also estimated sizable reductions in motorcycle operator fatalities after the implementation of a mandatory motorcycle helmet law in Texas. Finally, Kraus et al. (1994) concluded that the enactment of an unrestricted motorcycle helmet law in

Table 1

Comparison of dependent and independent variable means and standard deviations among all states and those with and without motorcycle helmet laws

\begin{tabular}{|c|c|c|c|c|}
\hline & & $\begin{array}{l}\text { All states } \\
(n=51)\end{array}$ & $\begin{array}{l}\text { States with helmet laws } \\
(n=26)\end{array}$ & $\begin{array}{l}\text { States without helmet laws } \\
(n=25)\end{array}$ \\
\hline \multirow{3}{*}{$\begin{array}{l}\text { Dependent } \\
\text { variables }\end{array}$} & Deaths per 10000 registered motorcycles & $6.39 \pm 4.12$ & $7.04 \pm 4.58$ & $5.72 \pm 3.74$ \\
\hline & Number of deaths & $41.14 \pm 44.34$ & $50.55 \pm 53.25$ & $31.36 \pm 29.95$ \\
\hline & Motorcycle registrations & $73584 \pm 84621$ & $86155 \pm 103804$ & $60510 \pm 56180$ \\
\hline \multirow{10}{*}{$\begin{array}{c}\text { Independent } \\
\text { variables }\end{array}$} & State helmet law $($ yes $=1$, no $=0$ ) & $0.51 \pm 0.50$ & 1.00 & 0.00 \\
\hline & $\begin{array}{l}\text { State population density (residents per } 10 \text { square } \\
\text { miles) }\end{array}$ & $34.47 \pm 125.01$ & $53.98 \pm 172.01$ & $14.18 \pm 22.22$ \\
\hline & Average state temperature $\left({ }^{\circ}\right)^{\mathrm{a}}$ & $52.37 \pm 8.47$ & $55.15 \pm 7.34$ & $49.48 \pm 8.65$ \\
\hline & Average state precipitation (in. per month) & $3.25 \pm 1.37$ & $3.78 \pm 1.13$ & $2.70 \pm 1.40$ \\
\hline & State per capita alcohol consumption (gallons) & $2.29 \pm 0.54$ & $2.25 \pm 0.56$ & $2.33 \pm 0.52$ \\
\hline & Maximum state speed limit (miles per $\mathrm{h}$ ) & $64.58 \pm 4.76$ & $64.17 \pm 4.44$ & $65.00 \pm 5.07$ \\
\hline & Urban roads per State (percentage of lane miles) & $25.40 \pm 20.54$ & $29.79 \pm 21.91$ & $20.83 \pm 18.05$ \\
\hline & $\begin{array}{l}\text { Average engine displacement of decedent } \\
\text { motorcycles }(\mathrm{cc})^{\mathrm{a}}\end{array}$ & $873.78 \pm 115.46$ & $836.01 \pm 95.16$ & $913.05 \pm 122.04$ \\
\hline & Average age of decedents (years) & $32.59 \pm 3.72$ & $31.90 \pm 3.19$ & $33.31 \pm 4.10$ \\
\hline & State median age (years) & $35.39 \pm 1.81$ & $35.24 \pm 1.50$ & $35.54 \pm 2.09$ \\
\hline
\end{tabular}

\footnotetext{
${ }^{a}$ Indicates a statistically significant difference, $P<0.05$, between states with helmet laws and those without helmet laws.
} 
Table 2

Comparisons of total deaths and death rates per year between states with full motorcycle helmet laws and those without full motorcycle helmet laws

1994

$\begin{array}{lc}\text { All states }(n=51) & 2170 \\ \text { States with helmet } & 1350 \\ \text { laws }(n=26) & \\ \begin{array}{l}\text { States without helmet } \\ \text { laws }(n=25)\end{array} & 820 \\ & \\ \text { All states }(n=51) & 6.10 \\ & (3.78,8.34) \\ \text { States with helmet } & 6.96 \\ \text { laws }(n=26) & (4.55,8.93) \\ \text { States without helmet } & 5.07 \\ \text { laws }(n=25) & (3.69,6.80) \\ & P=0.094\end{array}$

1995

2098

1326

772

5.43

$(3.86,7.64)$

6.13

$(4.51,8.13)$

4.99

(3.53, 6.54)

$P=0.099$
1996

2027

1267

760

5.60

$(3.69,6.93)$

6.15

(4.20, 7.39)

5.29

(3.51, 6.20)

$P=0.127$
Totals

(1994-1996)

6295

3943

2352

5.60

$(3.85,7.64)$

6.20

(4.20, 7.39)

5.07

$(3.53,6.58)$

$P=0.008$
California significantly reduced the incidence of motorcycle crash fatalities.

Nevertheless, valuable contradictory evidence has also been asserted in the nonmedical literature with respect to the safety effects of motorcycle helmets. Using a latent variable model to analyze data in a national sample of motorcycle riders, Goldstein (1986) found that helmets had no statistically significant effect on the probability of rider death. He further concluded that helmet legislation may not be as effective a policy as stricter enforcement of speed limits in preventing motorcycle rider deaths. This appreciation of speed, as a risk factor in motorcycle rider death, was suggestive of a risk-compensation effect among motorcycle riders. That is to say, motorcycle riders who wore helmets perceived their risk of death as lower and responded with greater risk taking in the form of increased speed thereby prompting stricter enforcement of State speed limits (Peltzman 1973; Underwood et al., 1993). With some success, Graham and Lee (1986) found evidence of a risk compensation effect in the years following the enactment of a State motorcycle helmet law detracting further from the perception that helmets were, on balance, protective.

The effectiveness of motorcycle helmet laws has been under heavy debate for over three decades. Federal legislative pressure in 1966, 1977, and 1991 created a cyclical pattern of State helmet law enactments and repeals (Insurance Institute for Highway Safety, 1997). Each time a battery of states changed their helmet laws, a corresponding battery of academic research studies sought to evaluate their changes. For the first time though, a recent NHTSA report highlighted the statistic that fatality rates are lower in states without helmet laws (National Highway Traffic Safety Administration, 2000) The report labels this discrepancy as 'myth' likely due to omitted variable biases. Although this seemingly inconsistent phenomenon deserves better analytic scrutiny, little direct evidence can be found in the medical or nonmedical literature that statistically addresses the discrepancy. This lack of explanation motivated our study.

We began our study by confirming the unadjusted difference in death rates between states with and those without motorcycle helmet laws. This difference did, indeed, statistically exist over our 3-year study period

Table 3

Results of random-effects generalized least squares regression ${ }^{a}$

Percentage change in deaths per 10000 registered motorcycles (natural log transformation)

State helmet law (yes $=1$, no $=0$ )

$-3.632(-21.661,14.397)$

State populat

$P=0.740$

density

$0.160(0.066,0.253)$

(residents per 10 square miles) $P=0.005$

Average state precipitation (in. $\quad-0.408(-6.769,5.953)$ per month)

Average state temperature $\left(^{\circ}\right)$

State per capita alcohol consumption (gallons)

$P=0.916$

$3.842(2.722,4.962) P<0.001$

$2.987(-14.660,20.633)$

Maximum state speed limit (miles per h)

Urban roads per state ( $\%$ lane miles)

$P=0.781$

$-0.844(-2.118,0.431)$

$P=0.276$

$-0.481(-1.062,0.101)$

$P=0.174$

Average engine displacement of decedent motorcycles $\left(\mathrm{cm}^{3}\right)$

Average age of decedents (years)

State median age (years)

$-0.016(-0.066,0.035)$

$P=0.610$

$-0.154(-1.697,1.389)$

$P=0.869$

$-2.267(-7.193,2.658)$

$P=0.449$

$R^{2}$

0.554

\footnotetext{
a The dependent variable, deaths per 10000 registered motorcycles, has been transformed using a natural-log function. $P$-values (below each coefficient estimate) and 90\% confidence intervals (in brackets) are also reported.
} 
from 1994 to 1996 . We concluded that the median death rate was 1.13 motorcyclists per 10000 registered motorcycles higher in states with full motorcycle helmet laws.

However, after multivariate statistical adjustments for the competing effects of other explanatory variables, the statistically higher rate of death in states with full motorcycle helmet laws was no longer evident. On the contrary, other explanatory variables were found to be more closely associated with changes in death rates. Among these other variables were State population density and average State temperature. Contrary to our original hypothesis, higher State population densities significantly corresponded with higher motorcycle rider death rates. The findings regarding average State temperatures, however, were in line with our original suppositions. Although it was not statistically significant, the regression coefficient for average State precipitation also agreed with our original hypothesis. We can conclude then that weather, as measured by temperature, and to some degree by precipitation, affects motorcycle rider fatality rates. This is likely a function of the length of the riding season in each state. States with higher temperatures and less precipitation (such as in the southwestern US) have longer riding seasons and therefore greater opportunity for motorcycle fatalities to occur whereas states with lower temperatures and more precipitation (such as in the northeastern US) have shorter riding seasons and fewer motorcycle fatalities.

As it stands, our study primarily suffers from the limited time period over which it was conducted. Although in one respect the fact that none of the states changed their motorcycle helmet laws from 1994 to 1996 allowed us the advantage of making observations 'in equilibrium', a longer period of analysis that included a sufficient number of states who experienced changes to their helmet laws might have produced different results. We did not pursue this longer analysis because we perceived that it did not directly address the statistic of higher motorcycle rider death rates in states with full helmet laws, a phenomenon that was not evident in earlier reports (Sosin et al., 1990).

This study weakens the claim that fatality rates are significantly lower in states without full motorcycle helmet laws. After statistically adjusting for the influences of other risk factors, the existence of a state helmet law was associated with lower motorcycle rider death rates. Therefore, repeal of existing motorcycle helmet laws should be considered very closely, if at all, by State legislators.

\section{Acknowledgements}

The authors would like to thank Mary J. Vassar, Peter Bacchetti, and two anonymous referees for re- viewing drafts of this paper. This project was funded in part by the Centers for Disease Control and Prevention (grant no. R49CCR903697).

\section{References}

Baker, S.P., O’Neill, B., Ginsburg, M.J., Li, G., 1992. The Injury Fact Book, second ed. Oxford University Press, New York.

Bolhofner, B., Carmen, B.A., Donohue, S.D., Harlen, K., 1994. Motorcycle accident injury severity, blood alcohol levels, insurance status, and hospital costs: a 4-year study in St. Petersburg, Florida. Journal of Orthopaedic Trauma 8 (3), 228-232.

Diggle, P.J., Liang, K., Zeger, S.L., 1995. Analysis of Longitudinal Data. Clarendon Press, New York, NY.

Federal Highway Administration, 2000. Office of Highway Information Management. Highway Statistics 1994, 1995, 1996. Washington, DC http://www.fhwa.dot.gov/ohim/ohimstat.htm.

Fleming, N.S., Becker, E.R., 1992. The impact of the Texas 1989 motorcycle helmet law on total and head-related fatalities, severe injuries, and overall injuries. Medical Care 30 (9), 832-845.

Glejser, H., 1969. A new test for heteroscedasticity. Journal of American Statistical Association 64, 316-323.

Goldstein, J.P., 1986. The effect of motorcycle helmet use on the probability of fatality and the severity of head and neck injuries: a latent variable framework. Evaluation Review 10 (3), 355-375.

Graham, J.D., Lee, Y., 1986. Behavioral response to safety regulation: the case of motorcycle helmet wearing legislation. Policy Sciences 19, 253-273.

Gujarati, D.N., 1988. Basic Econometrics, second ed. McGraw-Hill, pp. $574-575$.

Insurance Institute for Highway Safety, 1997. Facts state laws. Helmet laws. Charlottesville, VA, pp. 1-2.

Insurance Institute for Highway Safety, 1999. Deaths go up on interstate highways where higher speed limits are posted. Status Report. Charlottesville, VA, 34 (1) pp. 1-8.

Insurance Institute for Highway Safety, 2000. Highway Loss Data Institute. Maximum posted speed limits for passenger vehicles. State Laws, http://www.hwysafety.org/safety_facts/state_laws/ speed limit laws.htm.

Keeler, T.E., 1994. Highway safety, economic behavior, and driving environment. American Economic Review 84 (3), 684-693.

Kraus, J.F., Peek, C., McArthur, D.L., Williams, A., 1994. The effect of the 1992 California motorcycle helmet use law on motorcycle crash fatalities and injuries. Journal of American Medical Association 272 (19), 1506-1511.

Lott, N., 2000. Monthly climatic surface data. US Department of Commerce, National Oceanic and Atmospheric Administration, National Climatic Data Center. http://www.ncdc.noaa.gov/ol/ climate/climatedata.html.

Lund, A.K., Williams, A.F., Womack, K.N., 1991. Motorcycle helmet use in Texas. Public Health Reports 106 (5), 576-578.

Mock, C.N., Maier, R.V., Boyle, E., Pilcher, S., Rivara, F.P., 1995. Injury prevention strategies to promote helmet use decrease severe head injuries at a level I trauma center. Journal of Trauma-Injury Infection and Critical Care 39 (1), 29-33 discussion 34-5.

Muelleman, R.L., Mlinek, E.J., Collicott, P.E., 1992. Motorcycle crash injuries and costs: effect of a reenacted comprehensive helmet use law. Annals of Emergency Medicine 21 (3), 266-272.

National Highway Traffic Safety Administration, 1996. Traffic safety facts 1995. Motorcycles, National Center for Statistics and Analysis, Washington, DC, pp. 1-8.

National Highway Traffic Safety Administration, 1998. Report to Congress. The effect of increased speed limits in the post-NMSL era. Washington, DC, pp. 1-43. 
National Highway Traffic Safety Administration, 1999. State legislative fact sheets. Motorcycle helmet use laws. National Center for Statistics and Analysis, Washington, DC, pp. 1-10.

National Highway Traffic Safety Administration, 2000. Without motorcycle helmets we all pay the price. http://www.nhtsa.gov/people/injury/pedbimot/safebike/Washington, DC.

National Institute on Alcohol Abuse and Alcoholism, April 2000. Databases-per capita alcohol consumption, based on alcohol sales data. http://silk.nih.gov/silk/niaaa1/database/qf.htm.

Peek-Asa, C., Kraus, J.F., 1996. Alcohol use, driver, and crash characteristics among injured motorcycle drivers. Journal of Trauma 41 (6), 989-993.

Peltzman, S., 1973. The effects of automobile safety regulation. Journal of Political Economy 83 (4), 677-726.

Rowland, J., Rivara, F., Salzberg, P., Soderberg, R., Maier, R., Koepsell, T., 1996. Motorcycle helmet use and injury outcome and hospitalization costs from crashes in Washington State. American Journal of Public Health 86 (1), 41-45.
Sarkar, S., Peek, C., Kraus, J.F., 1995. Fatal injuries in motorcycle riders according to helmet use. Journal of Trauma 38 (2), 242 245.

Soderstrom, C.A., Dischinger, P.C., Ho, S.M., Soderstrom, M.T., 1993. Alcohol use, driving records, and crash culpability among injured motorcycle drivers. Accident Analysis and Prevention 25 (6), 711-716.

Sosin, D.M., Sacks, J.J., Holmgreen, P., 1990. Head injury-associated deaths from motorcycle crashes: relationship to helmet-use laws. Journal of American Medical Association 264 (18), 2395-2399.

Underwood, G., Jiang, C., Howarth, C.I., 1993. Modeling of safety measure effects and risk compensation. Accident Analysis and Prevention 25 (3), 277-288.

Yax, L.K., 2000. State population projections. U.S. Department of Commerce, Census Bureau, Population Division, Population Projections Branch. http://www.census.gov/population/www/projections/stproj.html. 